\title{
Discutindo gênero na educação profissional e tecnológica: conquistas, desafios, tabus e preconceitos*
}

\author{
Tânia Gracieli Vega Incerti** \\ Lindamir Salete Casagrande $e^{* * *}$
}

\section{Resumo}

O objetivo deste artigo é analisar de que forma as questões de gênero fazem parte do cotidiano escolar, e, a partir da percepção de estudantes matriculadas/os nos cursos de Técnico em Mecânica e Técnico em Processos Fotográficos, do Instituto Federal do Paraná - Campus Curitiba, compreender se elas/eles identificam ou não desigualdades de gênero no seu percurso formativo. Como técnica de pesquisa utilizou-se a entrevista semiestruturada, aplicada a vinte e quatro estudantes dos referidos cursos. Os resultados da pesquisa apontam que as questões de gênero estão imbricadas e naturalizadas em todo o processo educativo do IFPR.

Palauras-chave: Educação Profissional e Tecnológica, Relações de Gênero, Mulheres e Tecnologia.

\footnotetext{
* Recebido em 13 de outubro de 2018, aceito em 22 de dezembro de 2020.

** Doutoranda em Tecnologia e Sociedade pela Universidade Tecnológica Federal do Paraná (UTFPR); pesquisadora do Núcleo de Gênero e Tecnologia (GeTec); assistente Social no Instituto Federal do Paraná, Curitiba, PR, Brasil. taniag_vega@yahoo.com.br / https://orcid.org/0000-0002-7700-4259

*** Professora aposentada da UTFPR; professora voluntária do Programa de Pós-Graduação em Tecnologia e Sociedade (PPGTE) da UTFPR; coordenadora do Núcleo de Gênero e Tecnologia (GeTec). Editora dos Cadernos de Gênero e Tecnologia, Curitiba, PR, Brasil. lindasc2002@gmail.com / https://orcid.org/0000-0002-8233-229X
} 
Discussing Gender in Vocational-Technical High School Education:

Achievements, Challenges, Taboos and Prejudices

\begin{abstract}
The objective of this article is to analyze how gender issues are part of common school practices and to understand, through the perception of students enrolled in courses for mechanical technicians and for technicians in photographic processes at the Vocational-Technical High School at the Federal Institute of Paraná -Curitiba campus, whether they identify gender inequalities in their educational careers. The research methodology involved semi-structured interviews issued to twenty-four students in the courses. The survey results indicate that gender issues are intertwined with and naturalized in the entire educational process at the vocational school.
\end{abstract}

Keywords: Vocational-Technical Education; Gender Relations; Women and Technology. 


\section{Introdução}

Para iniciarmos o debate a que pretendemos nesse artigo parte-se do pressuposto que a educação permeia algumas instituições sociais, dentre elas, e de modo especial, a escola. O espaço, onde se dão as relações sociais e econômicas em que as instituições de ensino estão inseridas, é dinâmico e está em constantes transformações, o que indica diversos desafios ao processo educacional. É nesse processo que reside a potencialidade da escola em se instituir como o locus privilegiado, com potencial para mudanças, bem como de constituir-se como um lugar no qual, muitas vezes, se manifestam desigualdades - particularmente, levando-se em consideração a discussão a que se propõe neste artigo, a desigualdade de gênero.

Tendo em vista essa conjuntura, ao delinearmos algumas considerações sobre a questão da igualdade, retoma-se a discussão proposta por Joan Scott (2005), para a qual, ao se ter em vista esse conceito como uma expressão meramente numérica, dispomos como significado quantidades idênticas de coisas, o que não é adequado para esse estudo. Quando se pensa no contexto social, sua definição é menos precisa e apresenta alguns paradoxos. Não se pode deixar de considerar, ainda, que

A igualdade é um princípio absoluto e uma prática historicamente contingente. Não é a ausência ou a eliminação da diferença, mas sim o reconhecimento da diferença e a decisão de ignorá-la ou de levá-la em consideração (Scott, 2005:15).

Nesse sentido, de acordo com o Caderno de Indicadores do Instituto Brasileiro de Geografia e Estatísticas (IBGE, 2013), as estatísticas recentes sobre as mulheres brasileiras mostram que elas estão cada vez mais presentes no mercado de trabalho e com níveis de escolaridade mais elevados do que os homens. No entanto, quando se considera a inserção da mulher em algumas carreiras profissionais, como as áreas técnicas e tecnológicas, essa realidade ainda apresenta muitas desigualdades no acesso.

Direcionando o olhar aos cursos de educação profissional e tecnológica, espaço escolhido para realizarmos esta pesquisa, concordamos com Maria Lúcia Büher Machado (2012), para quem as assimetrias de gênero também se manifestaram na organização do ensino Técnico industrial ${ }^{1}$. A autora, ao analisar a formação profissional e modernização no Brasil no período de 1930 a 1960 , expõe que as práticas educativas e pedagógicas, constantes na organização curricular das escolas de ensino industrial e técnico, envolviam conteúdos diferenciados para homens e mulheres. Com base no contexto anteriormente citado, é importante questionarmos: essa delimitação de áreas $e$ assimetrias de poder ainda persiste na Educação Profissional e Tecnológica? Discute-se gênero nesse âmbito? Qual o espaço das mulheres em um curso de predominância masculina? Estando elas inseridas em um curso no qual são maioria, qual é sua percepção sobre as relações de gênero? E os homens inseridos nesse contexto, percebem as desigualdades de gênero?

Diante dessas angústias, propôs-se uma pesquisa que tinha por objetivo geral compreender as relações de gênero na educação profissional e tecnológica, tendo por base o estudo dos projetos pedagógicos e a percepção de pessoas matriculadas nos cursos Técnico em Mecânica e Técnico em Processos Fotográficos do Instituto Federal do Paraná, Campus Curitiba que resultou na dissertação intitulada Brincadeiras persistentes, desigualdades de gênero presentes: Relações de gênero na Educação profissional, uma análise a partir da percepção de estudantes do IFPR - Campus Curitiba. E é parte dos resultados desta pesquisa que pretendemos trazer à tona neste artigo, especialmente delineando as percepções das/os estudantes no que se refere às relações entre colegas e com as/os professoras/es e a contribuição da escola na minimização das desigualdades de gênero.

\footnotetext{
1 A partir da Lei de Diretrizes e Bases da Educação (LDB), Lei 9.394/96, adota-se a denominação educação profissional para esse nível de ensino.
} 


\section{Locus e Metodologia da Pesquisa}

O Instituto Federal do Paraná (IFPR) tem sua história iniciada a partir da Escola Técnica da Universidade Federal do Paraná e como outras instituições federais de educação tecnológica e profissional, é fruto da Lei 11.892 de 2008. Com a promulgação da referida lei foram criados 38 Institutos Federais de Educação (IFs), Ciência e Tecnologia pela transformação dos antigos Centros Federais de Educação Tecnológicas (CEFETs), escolas agrotécnicas e escolas técnicas. Com essas instituições, houve a introdução de um novo modelo de educação profissional no país, que oferece cursos Técnicos de nível médio, cursos superiores de tecnologia, licenciaturas, mestrados $e$ doutorados, possibilitando ao estudante construir um itinerário formativo que se aproxime de suas expectativas e necessidades, além de proporcionar que o/a estudante tenha, desde o nível médio, acesso a uma formação de qualidade, com professores/as pós-graduados/as, bem como, participe ativamente de atividades e projetos de pesquisa e extensão.

Atualmente, o IFPR está em funcionamento com $25 \mathrm{camp}^{2}$. Os cursos ofertados nos diversos campi da instituição englobam os níveis médio e superior. Para o ingresso na instituição, na maioria dos cursos ofertados ${ }^{3}$, é necessário que a/o estudante passe por um processo seletivo. Esse processo é regido por edital anual e gradualmente vem incorporando em suas formas possibilidades de acesso diferenciadas por meio de vagas destinadas a determinadas cotas, como, por exemplo, sociais e raciais.

Curitiba, espaço em que realizamos a pesquisa, foi o primeiro campus do IFPR a ser implantado. Encontra-se em funcionamento em um prédio histórico, localizado na região central da capital paranaense.

É importante destacar que a escolha do local da pesquisa não se deu de forma aleatória. Trata-se de uma escola incluída no rol das instituições federais que contemplam a Rede Federal de Ensino. Essa escola disponibiliza à sociedade a oferta de vinte e quatro cursos técnicos: desses, oito são integrados ${ }^{4}$ ao ensino médio, e dezesseis são subsequentes a esse nível de ensino. Além dos cursos técnicos, a instituição também oferece três cursos superiores. A escola funciona nos três turnos e tem uma diversidade de pessoas, interesses e percepções que fazem parte do seu corpo acadêmico/escolar. Também se trata de uma instituição que, apesar de se constituir a partir da criação da Rede Federal de Educação Profissional em 2008, tem um histórico consistente no que se refere à oferta de cursos técnicos.

Dois cursos com características bastante distintas foram selecionados como universo da pesquisa. A escolha dos cursos Técnico em Mecânica e Técnico em Processos Fotográficos definiuse essencialmente por duas características específicas desses cursos: primeiro, pelo fato de que ambos são ofertados nas duas formas (integrado e subsequente); segundo, a partir do acompanhamento das matrículas em 2015, observou-se uma diferença excessiva no que se refere à entrada de homens e mulheres aos mesmos.

Essa diferença pode ser observada conforme disposto na tabela 1:

\footnotetext{
2 Assis Chateaubriand, Astorga, Barracão, Campo Largo, Capanema, Cascavel, Colombo, Coronel Vivida, Curitiba, Foz do Iguaçu, Goioerê, Irati, Ivaiporã, Jacarezinho, Jaguariaíva, Londrina, Palmas, Paranaguá, Paranavaí, Pinhais, Pitanga, Quedas do Iguaçu, Telêmaco Borba, Umuarama e União da Vitória, e ainda a modalidade do Ensino a Distância (EAD). Informação obtida na página oficial da instituição [http://reitoria.ifpr.edu.br/ - acesso em: 02 set. 2018].

3 Com exceção dos cursos de curta duração, como aqueles de Formação Inicial Continuada e ofertados pelo Programa Nacional de Acesso ao Ensino Técnico e Emprego (Pronatec).

${ }^{4}$ Cursos Integrados são aqueles em que o/a estudante tem possibilidade de realizar, ao mesmo tempo o ensino médio $e$ um curso técnico. Cursos subsequentes são aqueles em que o/a estudante já teve ter concluído o ensino médio, ou seja, são cursos técnicos pós-médio.
} 
Tabela 1: Matrículas de Mecânica e Processos Fotográficos em 2015

\begin{tabular}{c|c|c|c|c|c}
\hline Curso Técnico & $\begin{array}{c}\text { Total } \\
\text { Matrículas }\end{array}$ & $\begin{array}{c}\mathrm{N}^{\circ} \text { de } \\
\text { Mulheres }\end{array}$ & $\begin{array}{c}\mathrm{N}^{\circ} \text { de } \\
\text { Homens }\end{array}$ & \% Mulheres & $\%$ Homens \\
\hline $\begin{array}{c}\text { Mecânica } \\
\text { Integrado }\end{array}$ & 119 & 30 & 89 & $25 \%$ & $75 \%$ \\
\hline $\begin{array}{c}\text { Mecânica } \\
\text { Subsequente }\end{array}$ & 146 & 14 & 132 & $9,6 \%$ & $90,4 \%$ \\
\hline $\begin{array}{c}\text { Processos } \\
\text { Fotográficos } \\
\text { Integrado }\end{array}$ & 132 & 119 & 13 & $90,2 \%$ & $9,8 \%$ \\
\hline $\begin{array}{c}\text { Processos } \\
\text { Fotográficos } \\
\text { Subsequente }\end{array}$ & 131 & 94 & 37 & $72 \%$ & $28 \%$ \\
\hline
\end{tabular}

Fonte: Sistema Integrado de Gestão de Atividades Acadêmicas - Instituto Federal do Paraná. Consulta em 22 de setembro de 2015 - Elaboração própria.

Diante disso, justificamos a escolha da instituição e dos cursos e ponderamos que, além da análise da questão de gênero e diferença nos números de acesso por mulheres e homens presentes inversamente nesses cursos, será possível contemplar a percepção de diversidade geracional. Isso justifica-se visto que as/os estudantes que cursam ensino médio integrado constituem-se, em sua maioria, por adolescentes de 14 a 17 anos. Já as/os estudantes matriculadas/os em cursos subsequentes são jovens, com faixa etária acima dos dezessete anos.

Como técnica de pesquisa, utilizou-se a entrevista semiestruturada. De acordo com Maria Cecília Minayo (2013), a entrevista tem como matéria-prima a fala das/os interlocutoras/es. Menga Ludke e Marli André (2013:40) apontam que, diferentemente de outras técnicas, a entrevista, por seu caráter de interação, não estabelece uma relação hierárquica entre a/o pesquisadora/r e a/o pesquisada/o. Além disso, ela "[...] ganha vida ao se iniciar o diálogo entre entrevistador $e$ entrevistado". Conforme essas autoras, a grande vantagem da entrevista é o fato de que ela permite captar informações imediatas e correntes sobre os mais variados tópicos.

Dessa forma, a pesquisa realizada privilegiou a realização de entrevistas com 24 pessoas matriculadas nos cursos Técnico em Mecânica e Técnico em Processos Fotográficos. Destas, 12 de cada curso - seis do Técnico em Mecânica integrado, seis do Técnico em Mecânica subsequente, sete do Técnico em Processos Fotográficos integrado e cinco do Técnico em Processos Fotográficos subsequente. Acreditamos que o número proposto possibilita a garantia de uma pluralidade de vozes e percepções sobre o tema proposto no projeto desta dissertação.

A escolha das/os entrevistadas/os foi aleatória e de acordo com o interesse em participar da pesquisa, buscando-se preservar a divisão numérica igualitária entre mulheres e homens (doze estudantes de cada sexo).

\section{Gênero: uma categoria de e para a análise da realidade social}

Ao buscarmos a definição gramatical da palavra "gênero" no dicionário Aurélio, observa-se a informação de que essa palavra vem do latim e significa "classe" ou "espécie". A partir dessa definição, gênero pode servir como categoria gramatical para indicar se uma palavra pode ser classificada como feminina, masculina ou neutra. Para além da descrição gramatical, Guacira Lopes Louro (1996) destaca que o uso antropológico da palavra passou a ganhar sentido com as feministas de língua inglesa, estadounidense ou inglesas, que empregaram a expressão "gênero" com objetivo de enfrentar e combater a argumentação de cunho determinista biologicista ao explicar as diferenças entre os sexos.

Conforme acentua Joana Maria Pedro (2005:78),

O uso da palavra 'gênero' [...] tem uma história que é tributária de movimentos sociais de mulheres, feministas, gays e lésbicas. Tem uma trajetória que acompanha a luta por direitos civis, direitos humanos, enfim, igualdade e respeito. 
Buscando nos aproximar deste conceito, a partir de sua conotação antropológica, recorremos a Maria Amélia de Almeida Teles (2006), a qual destaca que os estudos feministas ao terem por base a categoria gênero, desmascaram as explicações usualmente utilizadas de que as diferenças biológicas tornam as mulheres inferiores. Podem ainda, denunciar ideologias e mentalidades que, no dia a dia, escondem as desigualdades sociais, econômicas, políticas e culturais entre os sexos, visualizando-se situações que mostram como o poder masculino tem subordinado a população feminina.

Muitos são os entendimentos e abordagens no que se refere à compreensão e sentido de gênero ${ }^{5}$, no entanto, é a partir do cenário de luta nos anos 1980 que o conceito de gênero vislumbrado como instrumento capaz de revelar e mensurar as desigualdades e conflitos entre os sexos começa a ser utilizado. Para além de uma categoria descritiva, segundo Scott (1995), gênero deve ser uma categoria analítica, uma categoria útil para a análise, tal como posto pela autora. Esse sentido surgiu no fim do século XX.

Conforme apontado pela autora, em muitas análises da realidade, a atenção dada ao gênero não é explícita, no entanto, ela ratifica a importância dessa categoria como parte crucial ao se analisar a organização da igualdade e da desigualdade. Para que se possa compreender as estruturas hierárquicas, são necessárias "[...] compreensões generalizadas das assim chamadas relações naturais entre homem e mulher" (Scott, 1995:91).

A partir da proposição de gênero como contextual ou relacional, conforme Claudia de Lima Costa (1994:161), é possível entender gênero como "[...] processos também moldados por escolhas individuais e por pressões situacionais compreensíveis somente no contexto social da interação social". Destaca a autora que, a partir dessa abordagem, linguagem e gênero deixam de ser concebidos como sistemas monolíticos para serem apreendidos como configurações complexas, múltiplas e heterogêneas.

Ratifica-se que nessa pesquisa levamos em conta a definição de gênero como uma categoria de análise histórica e social imprescindível para discussão sobre as relações de poder na sociedade, que se estabelecem pelas diferenças entre homens e mulheres, homens e homens e mulheres $e$ mulheres. Ademais, como propõe Louro (2008) não se nega o aspecto biológico, mas se enfatiza a construção social e histórica produzida sobre as características biológicas.

Acredita-se, tal como afirma Daniela Auad (2006), que, ao considerarmos as relações de gênero como socialmente construídas, é possível perceber uma série de características socialmente tidas como "naturalmente" femininas ou masculinas, relacionadas especialmente às relações de poder. Por fim, tal como posto por Teles (2006), a grande contribuição, ao se olhar a realidade com as lentes de gênero, tem sido a ênfase nos aspectos de socialização de mulheres e homens com vistas à construção de espaços igualitários para ambos, buscando-se a igualdade de direitos e de oportunidades, mas respeitando-se as diferenças.

\section{Apontamentos sobre gênero na educação}

Hoje, por se observar uma realidade em que as mulheres são a maioria nos bancos escolares, lutar pela igualdade nesse espaço parece sem valor. Mas será suficiente pensar que não há nada mais em uma escola que se traduza em desigualdade nas relações de gênero? Infelizmente, acreditamos que, ao se pensar nas relações de gênero e educação, situações de desigualdades ainda são vivenciadas. Como, quando e por que elas se manifestam? Na instituição que escolhemos para ser o foco desta pesquisa, situações de desigualdades de gênero são percebidas? É a partir dessas inquietações que se tem por finalidade discorrer sobre as relações de gênero e educação.

Para não iniciarmos expressando categoricamente que existem desigualdades de gênero na escola, recorre-se a Auad (2006:15, grifos da autora), a qual expõe que "[...] a escola pode ser um

\footnotetext{
${ }^{5} \mathrm{Na}$ dissertação Brincadeiras persistentes, desigualdades de gênero presentes: Relações de gênero na Educação profissional, uma análise a partir da percepção de estudantes do IFPR - Campus Curitiba, é possível encontrarmos uma descrição breve das diferentes abordagens e conceitos que a categoria gênero pode trazer. Aqui, priorizamos apontar somente o conceito que nos serviu de lente para guiar nosso olhar neste artigo.
} 
lugar onde se dá o discriminatório 'aprendizado da separação' ou, em contrapartida, [...] pode ser uma importante instância de emancipação e mudança".

Especialmente no que se refere à inserção das mulheres no espaço escolar, Eulalia Pérez Sedeño (2001) apresenta três momentos chave em que a luta para o acesso à educação foi recompensada: o Renascimento e da Revolução Científica, período em que as mulheres, de classes mais privilegiadas, começaram a aprender a ler e a escrever. Posteriormente, passado um século, a conquista foi por meio da possibilidade de acesso ao ensino superior e algumas academias de ciências para as demais mulheres ${ }^{6}$. Outro momento importante, conforme a autora ocorreu nos anos 60 do século XX e impulsionou a segunda onda do feminismo. Foi nesse período que se refletiu sobre os porquês de haver tão poucas mulheres estudando, inseridas nos espaços de trabalho e/ou nos espaços de liderança nas áreas científicas e tecnológicas, ainda que não houvesse nenhuma forma de discriminação legal/formal.

Consideramos que as condições para o acesso à educação atualmente tenham outro panorama. A partir da Constituição Federal de 1988, a educação constitui-se direito de todas/os. As mulheres, hoje, estão em vantagem numérica sobre os homens. Conforme dados do Relatório Educação para Todos no Brasil 2000-2015, as mulheres são maioria especialmente no ensino médio e superior, e, ao considerarmos a taxa de alfabetização da população de 15 anos de idade ou mais por gênero no período 2004 - 2012, "[...] percebe-se que esta taxa cresceu mais entre as mulheres, indo de $88,8 \%$ para $91,6 \%$, enquanto nos homens cresceu de $88,4 \%$ para $91,0 \%$ " (Brasil, 2014:46).

Em que pese à relação numérica entre os sexos no que se refere ao ensino médio, recorrendo à Síntese de Indicadores Sociais do IBGE 2015, verificamos que entre 2004 e 2014 a taxa de conclusão do ensino médio por pessoas de até 24 anos passou de $45,5 \%$ para $60,8 \%$, isso é, em uma década, mais da metade dessas/es jovens passou a ter pelo menos o ensino médio completo. No que se refere à comparação entre os gêneros, a taxa de conclusão do ensino médio era de $54,9 \%$ em 2014 para os homens, enquanto para as mulheres essa taxa atingiu 66,9\%, 12 pontos percentuais acima da dos homens. Conforme as conclusões dispostas nesse documento,

[...] a vantagem das jovens pode estar relacionada a papéis de gênero que direcionam os jovens mais cedo para o mercado de trabalho, fazendo com que eles conciliem mais frequentemente estudo e trabalho, agravando seu atraso escolar (Brasil, 2015:50).

Evidencia-se, conforme essa descrição, o entendimento de gênero a partir do desempenho de papéis sociais socialmente definidos para homens e para mulheres. Não se questiona que essas mulheres, que estão em vantagem por estarem estudando, também podem estar conciliando o trabalho remunerado com o trabalho doméstico e estudo.

Mas nesse contexto em que se observa uma igualdade no acesso à educação, como ficam as relações de gênero? Ainda se observam diferenciações de ensino ou atividades para meninos e para meninas? Entendemos, é claro, que atualmente não vivenciemos mais um tipo de educação claramente exclusivo para meninos ou para meninas. As escolas, hoje, são mistas. Entretanto, recorrendo a Auad (2006:55), é possível inferir que "[...] meninos e meninas apenas juntos, sem maiores reflexões pedagógicas sobre as relações de gênero, pode redundar em aprofundamento de desigualdades".

A autora, ao nos trazer os resultados de sua pesquisa em uma escola pública de ensino fundamental, pesquisa essa que tinha por objetivo conhecer as relações de gênero nas práticas escolares, destaca que

\footnotetext{
${ }^{6}$ Ressalta-se aqui, além da questão de gênero, o peso da classe e raça/etnia para a conquista desse acesso. Às mulheres negras e pobres esse acesso não era possibilitado.

7 Aqui mencionamos igualdade somente no que se refere à categoria gênero. Temos nitidez de que as condições para o acesso no que se refere às categorias de raça/etnia e classe ainda não se constituem em processos igualitários, especialmente no que se refere ao ensino superior.
} 
[...] os jogos e as brincadeiras dos quais participavam a maioria de meninas e meninos, no pátio, podem traduzir como as relações de gênero entre as crianças são construídas e, ao mesmo tempo, como se fabricam meninas, meninos, homens e mulheres (Auad, 2006:50).

Nesse sentido, ao pensarmos na relação da construção de identidades de gênero e a escola como partícipe desse processo, voltamo-nos a Louro (1997:27, grifos da autora), que afirma que "[...] tanto na dinâmica do gênero como na dinâmica da sexualidade - as identidades são sempre construídas, elas não são dadas ou acabadas num determinado momento".

No que se refere à construção de identidades de gênero, considera-se que essas se constroem sob a influência de alguns fatores, como, por exemplo, informações repassadas em casa, na escola, nos parques, por meio de brincadeiras infantis, por meio da mídia, da literatura etc.

Assim, argumentamos que as informações recebidas a partir do contexto em que a criança está inserida contribuem para a construção de sua identidade de gênero. Com isso, ratifica-se o importante papel da escola em não perpetuar estereótipos definindo cores, brinquedos, atividades e áreas para um ou outro sexo.

Retomando a contribuição teórica de Louro (1997), é possível inferir que a escola tem gênero, classe e raça. Todas essas categorias são expressas por meio do currículo, das atividades pedagógicas, brincadeiras no pátio, aulas de diversas disciplinas.

Conforme acresce Londa Schiebinger (2001), o processo de gênero continua da escola primária, perpassando todos os níveis de ensino. Para a autora, ainda que estejam na mesma classe e aprendendo por meio de um currículo único, meninos e meninas podem receber educações muito diferentes. "Da pré-escola à universidade, os professores tendem a escolher atividades de sala de aula que atraem mais os meninos que as meninas" (Schiebinger, 2001:119).

Nivaldo Moreira Carvalho (2010) contribui para a discussão sobre gênero e educação profissional. $\mathrm{O}$ autor parte de um estudo comparativo entre jovens do sexo masculino e jovens do sexo feminino, bem como entre cursos com características diferentes de uma instituição federal que oferta ensino médio integrado e aponta que as relações de gênero, manifestadas por situações discriminatórias, perpassam o cotidiano escolar desses/as jovens. São expressas nas atitudes dos colegas, dos docentes e por componentes da administração escolar. No entanto, nem sempre essas situações são visualizadas e apresentam-se como naturais para a comunidade escolar.

Iraci Pereira da Silva (2010:19), ao propor uma análise das relações de gênero na educação profissional, destaca que "desigualdades e diferenças mantidas pelas instituições de ensino estão implicadas nas relações de poder exercidas pelo currículo, método de avaliação e hierarquizações que desqualificam o sujeito".

Eleazar Venâncio Carrias (2011:62) menciona que

[...] especialmente na educação profissional, de tradição muito mais austera no Brasil do que outras modalidades, a pesquisa revelou que a questão da identidade do gênero e da orientação sexual é geralmente ignorada nos discursos docentes em sala de aula.

Nesse sentido, retomamos o argumento de Louro (1997:67, grifos da autora), no qual ela aponta que no espaço escolar "[...] tão ou mais importante do que escutar o que é dito sobre os sujeitos, parece ser perceber o não-dito, aquilo que é silenciado [...]".

Sendo assim, na sequência, apresentaremos o que as/os participantes da pesquisa disseram $e$ buscaremos perceber, também, o que foi silenciado.

As respostas encontradas e questão de gênero na educação profissional: as/os colegas, as/os professoras/es

Iniciamos esta seção trazendo para o debate as falas das/os entrevistadas/os no que se refere à lembrança de situações vivenciadas entre colegas, na sala de aula ou em outros espaços do IFPR que nos possibilitem compreender qual a percepção das/os estudantes quanto às relações de gênero nesse espaço de educação. O recorte principal das falas está em mostrar que ainda persistem relações e situações que expressam preconceitos contra a mulher, questionamentos quanto à orientação sexual das/os estudantes e a ideia socialmente difundida de que os cursos com 
predomínio de mulheres são desvalorizados. Esse recorte foi feito porque as respostas se apresentaram nas entrevistas dessa forma.

Anna Fridda ${ }^{8}$, estudante do curso técnico em Mecânica Integrado destaca que, nas atividades práticas, seus colegas a confrontam especialmente em situações em que se faz necessário o emprego de força. Nessas atividades, conforme expõe a estudante, há sempre um colega que questiona o fato dela ser feminista frente às situações que necessitam de força, e, tal como recorrentemente compreendido nas relações sociais, quem tem força são os homens.

A estudante também lembra que, quando ela entrou no IFPR, havia em sua turma nove mulheres e isso sempre foi tido como algo extraordinário, ainda que a turma fosse composta por 36 pessoas. Diante do que foi apontado pela estudante, parece ser ainda presente a ideia de que lugar de menina/mulher não é no curso Técnico em Mecânica. Esse argumento converge para o que aponta o estudo de Carvalho (2010) no que tange aos preconceitos que as mulheres enfrentam quando adentram em redutos masculinos. Vejamos o que nos trouxe a estudante:

$\mathrm{E}^{9}$ : Eles falam: Aquela coisa tipo, feminista só até a hora que tem que usar a força, essas coisas assim. E na questão de como se fosse ser uma coisa extraordinária que na minha turma tinha nove meninas, e todo mundo pensava, "meu Deus, que coisa extraordinária, porque tem tanta menina". Como se fosse algo uau, mas na verdade deveria ter mesmo (Anna Fridda, M.I. ${ }^{10}$ ).

Carmem, também do curso Técnico em Mecânica, destaca as brincadeiras que demonstram o quanto ainda se pensa que ali não é espaço de mulher e ratificam os estereótipos socialmente impostos, brincadeiras que apontam que lugar de mulher é em casa, cuidando dos afazeres domésticos. Os preconceitos disfarçados e negados durante a vida escolar da juventude, também foram relatados nos estudos de Silva (2010) nos quais observam-se brincadeiras ditas normais que, se analisadas com mais profundidade, trata-se da manutenção de discriminação e situações de diferenças entre jovens homens e jovens mulheres.

Voltando-nos ao depoimento de Carmen, ao final, a estudante menciona que, contrariando o que os seus colegas esperam, nas avaliações ela se sai melhor que eles. Tendo em vista que a estudante é dedicada e estudiosa, pode-se inferir que seus colegas, nas entrelinhas da reprodução da desigualdade de gênero por meio de brincadeiras preconceituosas, podem sentir-se inferiores, pois uma menina que ocupa um lugar que não é seu supera-os nas avaliações.

E: Sim, na minha sala, por ter pouca mulher, os homens brincam muito com isso. E isso me irrita muito.

E: Brincam falando, "ah, vai lavar louça. Ah, vai estender minha roupa". E daí a gente vai lá, chega na prova e tira uma nota maior que eles. (Carmem, M.I.)

Nesse mesmo sentido, Iracema relata um episódio vivenciado por ela em que, em uma determinada disciplina que envolvia motor de carro, foi solicitado pela/o professora/r que se fizesse trabalho coletivo, mas ninguém a escolheu. Aqui, é visível a exclusão vivenciada por essas meninas, as quais constantemente são questionadas quanto à sua capacidade e necessitam sempre se "superar". A fala da estudante converge ao argumento de Carla Giovana Cabral e Walter Antonio Bazzo (2005:7, grifos do/a autor/a), que ao analisarem carreiras científicas e tecnológicas, afirmam que "Comportamentos de exclusão geralmente 'insignificantes', que passam inadvertidos, mas criam, ao se acumularem, um clima hostil que dissuade (afastam) as mulheres a ingressar ou permanecer nas carreiras científicas e tecnológicas"

\footnotetext{
8 A partir desse momento apresentaremos alguns nomes próprios para designar as/os entrevistadas/os. Trata-se de nomes fictícios, preservando-se o anonimato das/os participantes.

${ }^{9}$ Nos excertos das entrevistas, a letra $\mathbf{P}$ indica fala/pergunta da pesquisadora e a letra $\mathbf{E}$, a fala da/o entrevistada/o.

${ }^{10}$ Nas análises das entrevistas utilizaremos a seguinte legenda: M.S. - Mecânica Subsequente; M.I. - Mecânica Integrado; PF.S. - Processos Fotográficos Subsequente; PF.I. - Processos Fotográficos Integrado.
} 
E: Tipo ano passado eu passei por isso. A gente estava fazendo um trabalho que envolvia motor de carro. E ninguém me escolheu para fazer parte, porque achou que eu não ia entender.

$\mathrm{P}$ : Dos alunos?

E: Dos alunos. Que eu não ia entender, eu fiz sozinha. Fui a única que tirou uma nota boa. (Iracema, M.I.)

Além das situações mencionadas anteriormente, há ainda o questionamento em relação ao porquê de elas escolherem o curso Técnico em Mecânica, como se ali realmente não fosse o seu lugar. Esse estranhamento também foi relatado por estudantes que participaram da pesquisa realizada por Casagrande e Lima e Souza $(2015,2016)$ com estudantes de engenharia e licenciatura, ou seja, muda-se o universo da pesquisa, mas o resultado é o mesmo. Helena lembra que sempre é questionada sobre o porquê de escolher o curso, denotando essa escolha como algo extraordinário:

E: Sempre que eu entro na sala alguém olha, "por que você escolheu Mecânica?" Tipo, "nossa, por que você está aqui?” (Helena, M.S.)

Interessante apontar que as estudantes entrevistadas do curso subsequente, inicialmente relataram que nunca vivenciaram situações de desigualdade de gênero pelo fato de escolherem ou estarem no curso.

P: E no desenvolver do curso, assim, tem alguma situação que você tenha visto que seja de desigualdade de gênero? (...)

E: Não, aqui não.

P: No curso não?

E: Não.

P: E você já ouviu alguma piada, comentário desagradável sobre as mulheres que fazem mecânica?

E: Também não, nunca escutei (risos). As pessoas ficam assustadas, na verdade, "Nossa, mecânica! Isso daí é coisa de piá, não é coisa de mulher fazer”. (...)

P: Isso você ouviu?

E: Sim.

E: (...) Igual na última aula que tinha de soldagem ali, tava todo mundo soldando, todo mundo foi experimentar como que soldava, daí o professor falou "venha você". No que eu fui coloquei lá tudo certinho e comecei fazer, daí eles "NOSSA, até a ENEDINA tá soldando melhor que muita gente". ATÉ. Eu segurei o negócio e disse "o que você quer dizer com isso, 'até eu"'? né, isso é nas pequenas coisas que a gente vê, mas não é toda hora (Enedina, M.S.).

As falas trazidas pela estudante demonstram uma certa naturalização das desigualdades de gênero por ela sofridas, todavia, é evidente que os comentários a incomodam. Essa negativa $e$ naturalização pode se constituir em um processo de defesa, em uma estratégia de sobrevivência em um ambiente que pode ser muito hostil para com as estudantes. Nesse sentido, é possível retomarmos a contribuição teórica de Betina Stefanello Lima (2013:886, grifos da autora), que, ao exemplificar as "fases" do labirinto de cristal vivenciado por mulheres cientistas, evidencia o conceito de "drible da dor". Conforme a autora, o drible da dor está relacionado ao

[...] não reconhecimento ou à minimização dos problemas associados ao gênero e à ascensão na carreira científica por parte das próprias cientistas. O drible da dor trata das manobras utilizadas pelas cientistas na recusa em perceber os obstáculos específicos do gênero dispostos ao longo de suas carreiras.

Destacamos que essas situações foram trazidas pelas meninas/mulheres. Os estudantes enfatizam que a turma é sempre muito respeitosa e que eles não observam nenhum tipo de diferenciação para com as mulheres. Ao mesmo tempo, os homens têm ciência de que as mulheres estão em uma situação de desigualdade e que, em algum momento, isso vai aparecer. André exemplifica o que estamos dizendo: 
E: Assim, no meu curso assim, até porque eram duas meninas só. A outra saiu e agora segue uma. Mas nunca assim teve, "ah, tu não vai se dar bem porque você é mulher". Nunca teve, eu acho que provavelmente vá sofrer isso quando entrar na indústria. Mas eu tenho certeza que na nossa turma não ocorre isso (André, M.S.).

Nesse sentido, observamos a contradição e negação posta na fala desse estudante. Destaca-se que André e Enedina fazem parte da mesma turma e, tal como vimos na fala da estudante, ela já vivenciou situações de desigualdade no que se refere a gênero. Uma possível explicação para essa divergência está no fato de que a dor é sentida pela/o oprimida/o e o/a opressor/a fica imune a esse processo, inclusive não reconhecendo suas atitudes como causas de opressão, tal como nos lembra Paulo Freire (2010).

Ao buscarmos conhecer as relações entre colegas no curso de Processos Fotográficos, as respostas, em sua maioria, direcionaram-se em mostrar que o curso é mais aberto e que há uma relação de amizade próxima. O que foi exposto, neste caso com maior ênfase pelas/os estudantes do curso na forma integrada, é o questionamento quanto à orientação sexual. Esse questionamento é feito, em geral, por estudantes de outras turmas. Enquanto as meninas que ingressam em áreas predominantemente masculinas têm sua capacidade questionada, os meninos, ao ingressarem em cursos nos quais a maioria dos/as estudantes são mulheres, têm sua sexualidade posta em julgamento. Este resultado converge com os encontrados por Casagrande e Lima e Souza (2015).

Gervásio e Rosa, em suas falas, trazem-nos isso:

$\mathrm{E}:($...). As pessoas meio que relacionam os meninos de PF com a nossa sexualidade. Então tipo, "ah, porque menino que faz PF é gay, menina que faz PF é lésbica". Eu acho que essa miscigenação do curso faz as pessoas pensarem nisso (Gervásio, PF.I).

E: A tudo, tanto de gênero, (...) orientação afetivo sexual, porque muita gente já chegou e falou assim, "você é muito bonita para namorar uma menina" (Rosa, PF.I).

Avançando para a discussão proposta nesta subseção, para além de observar a percepção das/os estudantes quanto às relações entre colegas intermediadas pelas relações de gênero, esperamos compreender o papel das/os professoras/es, buscando uma articulação com as possibilidades de permanência da/o estudante no ensino profissional e tecnológico. Entendemos que as/os professoras/as podem desempenhar tanto o papel de contribuição como o de dificultador da permanência da/o estudante em um curso em que ela/e é minoria na sala. Mas será que as/os estudantes compreendem esse papel? Qual sua percepção sobre isso? Foi com base nesses questionamentos que buscamos, na entrevista, trazer suas percepções.

Anna Fridda, estudante de Mecânica integrado, destaca que as/os professoras/es não necessariamente manifestam, em suas falas, desigualdade quanto aos aspectos intelectuais. No entanto, em tons de piada, "tratam" as meninas como algo frágil, que precisa ser protegido, convergindo para o que também foi apresentado por Casagrande e Lima e Souza (2015). Observemos a fala da estudante:

E: (...) o que a gente ouve é piadinha de professor tratando mulher como objeto, dando um exemplo de alguma coisa que aconteceu na vida dele mesmo, qualquer coisa, e tratar as meninas como objeto, ou aquela coisa, "essa parte deixa para os meninos porque vocês têm que ser protegidas" (Anna Fridda, M.I.).

A mesma estudante relata em sua entrevista como as mulheres são vistas como objetos e que são com frequência culpabilizadas e responsabilizadas por questões de assédio, por exemplo. A estudante destaca a necessidade de que as/os professoras/es, frente a situações de desrespeito, tragam o assunto para o debate, estimulando que todas/os as/os estudantes participem. No entanto, a estudante frisa que, antes disso, as/os professoras/es precisam entender que tais situações ferem $e$ são preconceituosas. Nesse sentido, ponderamos que o debate promovido por pessoas preconceituosas pode reforçar as situações de desrespeito, perpetuando a desigualdade de gênero. 
$\mathrm{E}$ : $\mathrm{Eu}$ acho que os professores deveriam trabalhar mais isso em aula e dar o exemplo. Porque até professores do núcleo comum mesmo falam coisas extremamente machistas, de colocar a mulher como a culpada sempre, culpabilização mesmo. Por exemplo, o professor de Educação Física já falou na sala sobre academia, essas coisas, falando que as mulheres começaram a usar legging só porque as mulheres queriam mostrar as pernas e coisa do tipo, para acentuar as curvas. Então acho que primeiro os professores tinham que começar a entender essas coisas. Porque tem muito professor que entende de trabalho, mas tem professor que nega tudo totalmente (Anna Fridda, M.I.).

Nas falas das/os estudantes, também foi possível perceber como há uma valorização das atitudes das/os professores no sentido de apoiar e promover um tratamento igualitário entre meninos e meninas. Assim, ratificamos a importância de que as/os professoras/es estejam preparadas/os para receber e estimular as/os estudantes que se encontram em um espaço que é socialmente definido como o do outro. Iracema, Alberto e Helena apontam isso. Observemos:

E: Professores (...), eles me apoiam bastante, porque sou a única menina da sala, eles querem que eu siga carreira. (...) (Iracema, M.I.).

E: (...) tem 2 meninas na sala, os professores tratam elas de maneira normal, tanto com relação a passar informações, quando elas têm dúvidas, como pelo simples fato de dar uma aula explicando para elas o que eles explicam para gente, tranquilamente (Alberto, M.S.).

E: Não, eles sempre tentam ajudar, eles tratam a gente como igual. Eles falam, "se vocês escolheram Mecânica, agora vocês vão ser tratadas como Mecânicas (...)” (Helena, M.S.).

A partir da fala da estudante Helena, observa-se que há a intenção por parte das/os professoras/es de um tratamento igualitário. Entretanto, ao destacarmos especialmente a frase repetida pela estudante "se vocês escolheram Mecânica, agora vocês vão ser tratadas como Mecânicas", acredita-se que, ao colocar isso de maneira expressiva, as/os professoras/es, nas entrelinhas, podem estar reafirmando ou colocando em xeque o lugar dessas estudantes no curso. Ou seja, "agora que vocês estão aqui vão ter que aguentar".

Enedina que, como observamos anteriormente, demorou a perceber que já havia sofrido situações de desigualdade de gênero, relata alguns acontecimentos vivenciados por ela no começo do curso que demonstram o quanto as mulheres, em espaços ocupados pela maioria masculina, sofrem desrespeito, são questionadas em suas habilidades e devem lutar para não serem engolidas por linguagens machistas que buscam colocá-las em um espaço de "rapaziada". Como é possível observar na resposta da estudante, podemos pensar que, implicitamente, falava-se no sentido de dizer que aquele não era seu espaço. Vejamos:

E: Não. No começo do curso eles faziam piadinha, tipo essas coisas. No começo, agora não. Mas no começo foram bem poucas assim. Até mesmo no negócio do professor chegar na sala e falar e "aí rapaziada". Tipo assim, é normal pros piás. (...). Eu falo "eu tô aqui, professor".

P: (...) Mas hoje não tem mais isso?

E: Não. Sem contar que no começo, nas outras do segundo semestre, quando a gente tinha aula no laboratório, eu começava a fazer as coisas e o professor falava "não, não precisa tocar", tipo, "não, não sei o quê". Eu, "por que não?". (...) Mas eu ia lá, segura o negócio e ele falava "não, não precisa, Enedina, deixa que o piá ali pega", mas eu dizia, "mas porquê, porquê" (...) é muito forte ali. Tá, mas um dia se eu precisar em uma empresa, tem que segurar, se só tiver eu lá, vou deixar? (...). (Enedina, M.S.)

A partir da fala trazida por Enedina, podemos perceber que em sala de aula estas estudantes sofrem o que Pierre Bourdieu (1999:7) denominou de violência simbólica. Para o autor, este tipo de violência é: 
[...] uma violência suave, insensível, invisível a suas próprias vítimas, que se exerce essencialmente pelas vias puramente simbólicas da comunicação e do conhecimento, ou, mais precisamente, do desconhecimento, do reconhecimento ou, em última instância, do sentimento.

Helena, do curso Técnico em Mecânica, destaca que, às vezes, as falas das/os professoras/es na sala são românticas no sentido de afirmar que as mulheres são tratadas de maneira igualitária, especialmente no mercado de trabalho. Essa estudante destaca que isso deveria ser melhor trabalhado no curso, aprofundando a discussão sobre as desigualdades de gênero presentes na sociedade.

E: (...) principalmente pela parte de terem mulheres no curso devia ter essa discussão de mercado de trabalho.

P: Por quê? Você acha que a mulher vai enfrentar diferenças lá fora?

E: Sim, eles falam que não, na sala eles falam que não, que não vai ter diferença, que vai ser tudo igual, eles acham que é tudo bonitinho, eles criam um mundo na mente deles. Mas a gente sabe, a gente sente a diferença (Helena, M.S.).

Diante disso, retomamos o que nos apresentou Louro (1997), para quem a escola é um espaço atravessado pelos gêneros, $e$, dessa forma, não se pode invisibilizar essa discussão e ignorar que situações de desigualdades ${ }^{11}$ de gênero ainda se fazem presentes nesse espaço, bem como em outros espaços da sociedade, tais como no mercado de trabalho.

Ao realizarmos a análise das entrevistas das/os estudante do curso Técnico em Processos Fotográficos, elas/es afirmaram, em vários momentos, que o curso é mais flexível. Uma possível explicação para tal afirmativa pode estar no fato de o curso estar relacionado às artes e à área de humanas, em que comumente se difunde isso. Conforme posto pelas/os estudantes do curso, suas/seus professoras/es são mais liberais, no entanto, ao direcionarmos o questionamento sobre possíveis vivências de desigualdade de gênero na entrevista, as/os estudantes informaram que essas situações também ocorrem no e sobre o curso.

Nair, estudante da forma integrada, aponta-nos que há uma desvalorização pelas/os professoras/es em relação ao fazer profissional do curso. Nesse sentido, voltamo-nos ao que nos apresenta Silvia Cristina Yannoulas (2011), que ao discutir o processo de feminilização, ou seja, o aumento expressivo de mulheres em uma área, observa que há diminuição das remunerações e desvalorização e desprestígio dessa área. Conforme a estudante:

E: É porque alguns professores, eles têm muito preconceito com PF, sabe "Ah, é um curso que não, vocês não fazem nada, só fica apertando o botão, tirando foto". (...) (Nair, PF.I.)

Essa estudante apresenta sua percepção convergindo para o que foi trazido pelas/os estudantes do curso de Mecânica em observar que falas preconceituosas de professoras/es ainda são recorrentes. Além das/os professoras/es, outras/os profissionais que fazem parte da comunidade escolar foram lembradas/os pela estudante como reprodutoras/es de situações de desigualdades.

E: (...) não só professores, mas existem, existe 1 inspetor no colégio que é extremamente homofóbico e transfóbico e todo mundo reclama disso, (...) (Nair, PF.I)

Rosa lembra em sua fala que algumas/uns professoras/es fazem comparações entre os cursos, especialmente entre aqueles em que há predominância maior no número de meninos, e Processos Fotográficos. Ao trabalhar um tema em que há contrariedade no debate na turma de Processos Fotográficos, especialmente quanto à piadinha de um professor, ele encerra o assunto afirmando que é muito mais difícil dar aula para Processos Fotográficos, pois na sala "ninguém concorda com ele", ou que a turma não quer que ele seja professor.

\footnotetext{
${ }^{11}$ Temos ciência de que outras desigualdades, tais como de classe, raça, dentre outras, também são realidade na escola, no entanto, neste artigo, não aprofundaremos esse debate.
} 
E: Eu tinha um professor ano passado que ele chegou na nossa sala, e está tendo todo esse negócio de crise essas coisas assim, e ele falou assim, "porque para um homem perder um trabalho é uma coisa muito ruim, é uma coisa muito pesada, não é tão pesada para uma mulher". E nisso a nossa turma ficou muito brava, muito brava, a gente chegou e falou, "meu, você acabou de falar uma coisa horrível agora". Porque não, é horrível para 2 pessoas perder o emprego, é uma renda a menos, do mesmo jeito que o homem tem que pagar as contas, mulher também tem que pagar as contas. E aí ele falou assim, porque ele dava aula ano passado para PF e Mecânica, e ele falou assim, "nossa, eu não consigo fazer, não consigo falar nada nessa sala, porque em Mecânica, as pessoas concordaram comigo, em Mecânica as pessoas concordaram comigo e aqui tipo vocês não concordam" (Rosa, PF.I.).

Com base no que foi posto pela estudante em que o professor preconceituosamente defende que o trabalho do homem tem mais valor na sociedade lembramo-nos do que nos trazem Helena Hirata e Danièle Kergoat (2007), quando as autoras informam que a divisão sexual do trabalho tem dois princípios organizadores: o princípio de separação - no qual se observa a distinção entre trabalhos de homens e trabalhos de mulheres - e o princípio hierárquico - o que significa dizer que o trabalho de homem tem mais valor que o trabalho de mulher.

A mesma estudante aponta ainda o preconceito no que se refere às relações homoafetivas na instituição. Conforme expõe a estudante, casais formados por menino e menina são respeitados $e$ aceitos na sala de aula. A situação apresenta configuração diferente quando se trata de um casal homoafetivo, sendo o assunto tratado de forma extraordinária.

E: (...) do tipo de ter um menino e uma menina abraçado na sala de aula e beleza. Tipo, pode sentar um do lado do outro, só que quando tem uma menina e uma menina, que isso já aconteceu comigo, fizeram uma reunião esses tempos para virem falar da gente, que a gente estava atrapalhando de alguma forma a aula dos professores, $e$ os professores não queriam vir falar com a gente pensando que ia ser, a gente ia achar isso como preconceito. Só que não, é como um casal normal, meu, não pode, você está em uma sala de aula (...). (Rosa, PF.I.)

Vilma e Cynthia, do mesmo curso, quando questionadas sobre os comentários das/os professoras/es, trazem em suas falas o problema do questionamento quanto à sexualidade das estudantes. Cynthia aponta ainda a "inferiorização" presente no discurso de um determinado professor que, de acordo com a estudante, foi motivo de uma reivindicação da turma, que pedia para que ele não mais lecionasse para o curso.

E: Os professores chegam na sala falando, "meninas, vamos fazer tal coisa". E daí os piás ficam tipo, "mas e a gente?" Daí o professor fica, "vocês estão em PF, vocês são tudo menina também, vocês são gays, vocês não são piás" (Vilma, PF.I).

P: Que tipo de comentários?

E: Ah, tipo, essa de lésbica ele fez dentro da sala, "garanto que vocês estão héteros ainda". Deu uma briga isso. E coisa de tratar a gente de um jeito inferior, sabe, menina, elas não ligam para Física, por exemplo, vou ensinar o básico só. E era bem absurdo, tanto que a gente brigou, a gente foi e tiraram ele, ele não dá mais aula para $\mathrm{PF}$, não deu no nosso ano pelo menos (Cynthia, PF.I.).

Nesse sentido, recordamos o que Auad (2006) nos apresenta como sendo a síntese do papel social da escola no que se refere às desigualdades de gênero, podendo ela ser uma instância de emancipação e mudanças ou um espaço em que se perpetuam ações discriminatórias de separação de aprendizados. 


\section{A contribuição da escola para a discussão das relações de gênero}

Por fim, dentre as propostas sugeridas pelos/as estudantes no que se refere à possíveis ações que contribuam com a igualdade de gênero no espaço escolar, essas são no sentido de que haja uma intensificação do debate, perpassando a sala de aula e outros espaços institucionais. Tal como têm consciência as/os estudantes, o Ensino Médio Integrado é uma fase da vida muito importante para a formação das identidades e, se não houver debates e discussões mais aprofundadas, prevalecerá a influência de outros meios, como os de comunicação de massa, que geralmente são de senso comum. Tal discussão é muito importante de ser realizada tanto em sala de aula quanto em todos os lugares, mas principalmente na no âmbito escolar, que é o lugar onde grande parte dos/as adolescentes passam a maior parte de seu tempo nesse espaço.

Gervásio e Cynthia do curso de Processos Fotográficos destacaram o fato de que a escola é importante e contribui com a questão ao realizar algumas ações que colaboram para a ampliação e transformação de suas visões quanto ao tema, diminuindo o preconceito e os estereótipos de gênero e, talvez, minimizando as desigualdades de gênero $e$ aumentando o respeito à diversidade.

Carmem, estudante do curso Técnico em Mecânica e Gervásio, de Processos Fotográficos, apresentam suas contribuições quanto à possíveis ações da escola:

E: Que nem eu falei, a educação de casa e a escola pode ajudar falando em sala de aula, em Sociologia, descreve o histórico da mulher, que ela não está aqui à toa, ela foi lá, teve o histórico, já teve que fazer muita coisa para conseguir entrar no mercado de trabalho e agora tem essa diferença? (Carmem, M.I.).

E: Eu acho que debater mais, levantar mais debates, mais discussões sobre isso, porque é uma realidade. E a gente está infiltrado nessa realidade. Então eu acho que não dá para esconder uma coisa assim, eu acho que dá para destacar esses assuntos. Acho que é isso (...). Promover mais ações (Gervásio, PF.I.).

As/os estudantes ressaltam as ações já desenvolvidas na instituição, as quais perpassam pelo trabalho em datas comemorativas ou semanas alusivas e são, em geral, desenvolvidas pelo Grêmio Estudantil e Núcleo de Apoio ao Estudante e ao Professor (NAEP) ${ }^{12}$, bem como de ações permanentes desenvolvidas pelo Núcleo de Gênero e Diversidade (NeGeDi) como momentos importantes para provocar a reflexão sobre a temática e tentar minimizar as manifestações de preconceito e as desigualdades de gênero no espaço escolar, porém insuficientes.

Para fecharmos as contribuições apresentadas pelas/os estudantes, trazemos a percepção do estudante Sebastião, do curso Técnico em Processos Fotográficos integrado, que, em longo depoimento, destaca que a escola também tem que rever suas ações com relação ao tema, pois ações distorcidas como a venda de lingerie, cursos de maquiagem já realizadas em comemoração ao dia da mulher, por exemplo, podem ter um resultado negativo quanto à possibilidade de igualdade de gênero, perpetuando estereótipos.

Outro questionamento apontado pelo estudante se refere aos cargos de coordenação de curso, que, a seu ver, são ocupados em sua maioria por homens. O estudante cita também o exemplo do Conselho Superior da Instituição que é majoritariamente masculino. Sebastião mostrase muito consciente do processo do qual muitas instituições de ensino, por receio dos pais ou mesmo do seu corpo docente, acabam não se apropriando e não proporcionando a discussão sobre gênero. Especialmente no âmbito nacional, vivemos hoje um momento de grande retrocesso e a escola está prestes a se tornar uma escola sem discussão, sem debate, à mercê de um Projeto de Lei que inclui entre as diretrizes e bases da educação nacional, de que trata a Lei ${ }^{\circ}$ 9.394, de 20 de dezembro de 1996, o Programa Escola sem Partido. Louro (1997) nos alerta que, tão importante quanto ouvir o que é dito, é escutar o que é silenciado. Enquanto a escola silenciar temas como gênero e diversidade, vai falhar em seu papel de formar cidadãs/ãos críticas/os e capazes de transformar as relações sociais.

\footnotetext{
${ }^{12} \mathrm{Na}$ época da realização da pesquisa era essa a denominação da Seção Pedagógica.
} 


\section{Algumas considerações}

A educação profissional e tecnológica tem um papel contraditório ao passo que dela se espera a formação para o mercado de trabalho ao mesmo tempo em que também se faz necessária uma formação mais completa e integral, vivenciando o debate de temas que não se reduzam aos indicativos de uma formação meramente tecnocrática. No IFPR observamos que há debates que visam ultrapassar a formação tecnocrática, no entanto, nesse espaço ainda se observam situações de desigualdade, manifestações de preconceitos e reforço de estereótipos.

A partir dos relatos das/os entrevistadas/os, observamos, tanto nas relações entre colegas, quanto nos discursos propagados por professoras/es em sala de aula, que as situações de desigualdade de gênero são realidade no IFPR.Essa observação é presente nas falas das/os estudantes dos dois cursos. No decorrer das entrevistas realizadas, as/os estudantes apontaram situações que podemos inferir como possíveis contribuições da escola na discussão de gênero, especialmente no que se refere à reflexão sobre as desigualdades presentes e arraigadas no ambiente escolar $e$ em outras instituições sociais $e$ ações que possam contribuir para a construção e/ou manutenção da (des)igualdade de gênero.

Tal como apresentado pela maioria das/os estudantes entrevistadas/os, argumentamos que promover o debate enriquece as discussões e possibilita reflexões sobre situações naturalizadas socialmente, mas que são permeadas de preconceitos e desigualdades. Desta forma, no ambiente escolar, a/o professora/r tem um papel muito importante, as relações com as/os colegas, dependendo da maneira como se dá, encarregam-se, muitas vezes, de promover uma discussão que é pouco realizada ou contribui para o abismo da desigualdade e preconceito no que se refere às relações de gênero.

Para finalizar, longe da pretensão de achar que a escola será o único processo e única instituição que precisa de transformação, consideramos que, além de ações nesse espaço, são necessárias intervenções que perpassem os vários setores da sociedade. Incluindo-se as políticas públicas de gênero e para a mulher, que tenham por objetivo a discussão de estereótipos e a alteração da divisão sexual que permeia a formação e o trabalho. Ademais, se faz necessário investimento na formação, especialmente das mulheres, para que essas possam entender e lutar por alterações na divisão sexual do trabalho, ampliando o acesso e permanência dessas em determinadas profissões ainda hoje majoritárias ou quase exclusivamente masculinas. Isso não significa que pensamos aqui que as mulheres devam ser as responsáveis por essa transformação, pelo contrário, compreendemos que o processo educativo deva ser a elas ampliado e, obviamente, todas as pessoas podem $e$ devem se beneficiar de uma educação que promova e pense em ações de igualdade de gênero, racial e de classe.

\section{Referências bibliográficas}

AUAD, Daniela. Educar meninas e meninos, relações de gênero na escola. São Paulo, Contexto, 2006.

BOURDIEU, Pierre. A dominação masculina. Rio de Janeiro, Bertrand Brasil, 1999.

BRASIL. Sintese de indicadores sociais. uma análise das condições de vida da população brasileira. IBGE, Coordenação de População e Indicadores Sociais. Rio de Janeiro, IBGE, 2015.

BRASIL. Relatório Educação para Todos no Brasil 2000-2015, Versão preliminar. Brasília, 2014 [http://portal.mec.gov.br/index.php?option $=$ com docman\&view $=$ download\&alias $=15774$-ept-relatorio06062014\&Itemid $=30192$ - acesso em: 6 jun. 2016].

BRASIL. Síntese de indicadores sociais. uma análise das condições de vida da população brasileira. IBGE, Coordenação de População e Indicadores Sociais. Rio de Janeiro, IBGE, 2013.

BRASIL. Lei $n^{\circ} 11.892$, de 29 de dezembro de 2008. Institui a Rede de Educação Profissional Científica e Tecnológica e cria os Institutos Federais de Educação, Ciência e Tecnologia. Brasília, DF, 29 de dezembro de 2008 [http://www.planalto.gov.br/ccivil_03/_ato2007-2010/2008/lei/111892.htm - acesso em: 15 maio 2016].

BRASIL. Lei $n^{\circ}$ 9.394, de 20 de dezembro de 1996. Institui as Diretrizes e Bases da Educação Nacional. Brasília, DF, 20 de dezembro de 1996. 
CABRAL, Carla Giovana; BAZZO, Walter Antonio. As mulheres nas escolas de engenharia brasileiras: história, educação e futuro. Revista de Ensino de Engenharia, v. 24, n. 1, 2005, pp.3-9.

CARRIAS, Eleazar Venâncio. Relaçôes de gênero, subjetividade e construção/constituição de identidades. um caso na educação profissional e tecnológica. Dissertação (Mestrado em Educação), Universidade de Brasília, Brasília, 2011 [http://repositorio.unb.br/handle/10482/11992 - acesso em: 20 nov. 2015].

CARVALHO, Nivaldo Moreira. Ensino médio integrado, representaçóes de gênero e perspectivas profissionais: um estudo com jovens dos cursos de agropecuária e agroindústria em Guanambi/BA. Dissertação (Mestrado em Educação), Universidade de Brasília, Brasília, 2010. [http://repositorio.unb.br/handle/10482/9106 - acesso em: 20 out. 2015].

CASAGRANDE, Lindamir Salete; SOUZA, Angela Maria Freire de. Violência simbólica de gênero em duas Universidades Brasileiras. In: WANZINACK, Clóvis; SIGNORELLI, Marcos Claudio (org.). Violência, gênero e diversidade: Desafios para a educação e o desenvolvimento. Curitiba, UFPR, 2015, v. 1, pp.79108.

CASAGRANDE, Lindamir Salete; LIMA E SOUZA, Ângela Maria Freire de. Para além do gênero: mulheres e homens em engenharias e licenciaturas. Revista Estudos Feministas, 24(3), Florianópolis, set./dez./2016, pp.825-850.

COSTA, Claudia de Lima. O leito do procusto: Gênero, linguagem e as teorias feministas. cadernos pagu (2), Campinas-SP, Núcleo de Estudos de Gênero-Pagu/Unicamp, 1994, pp.141-174.

FREIRE, Paulo. Educação como prática da liberdade. 33 Imp. Rio de Janeiro, Paz e Terra, 2010.

HIRATA, Helena; KERGOAT, Danièle. Novas configurações da divisão sexual do trabalho. Cadernos de Pesquisa, v. 37, n. 132, set./dez. 2007, pp.595-609. Tradução de Fátima Murad [http://www.scielo.br/pdf/cp/v37n132/a0537132.pdf - acesso em: 01 abr. 2020].

LIMA, Betina Stefanello. O labirinto de cristal: as trajetórias das cientistas na Física. Revista Estudos Feministas 21 (3) Florianópolis, set-dez/2013, pp.883-90.

LOURO, Guacira Lopes. Gênero e sexualidade: pedagogias contemporâneas. Proposições, v. 19, n. 2 (56), maio/ago. 2008, pp.17-23.

LOURO, Guacira Lopes. Gênero, sexualidade e educação: uma perspectiva pós-estruturalista. Petrópolis, RJ, Vozes, 1997.

LUDKE, Menga; ANDRÉ, Marli E.D.A. Pesquisa em educação: abordagens qualitativas. 2. ed. Rio de Janeiro, E.P.U., 2013.

MACHADO, Maria Lucia Büher. Formação profissional e modernização no Brasil (1930-1960): uma análise à luz das reflexões teórico-metodológicas de Lucie Tanguy. Educação e Sociedade, v.33 n.118, Campinas, Jan./Mar. 2012, pp.97-114.

MINAYO, Maria Cecilia de Souza. O Desafio da pesquisa social. In: DESLANDES, Suely Ferreira; GOMES, Romeu; MINAYO, Maria Cecília de Souza (org.). Pesquisa social: teoria, método e criatividade. 33. ed. Petrópolis, RJ, Vozes, 2013.

PEDRO, Joana Maria. Traduzindo o debate: o uso da categoria gênero na pesquisa histórica. História [online], v. 24, n.1, 2005, pp.77-98 [http://www.scielo.br/pdf/his/v24n1/a04v24n1.pdf - acesso em12 set. 2016].

SCHIEBINGER, Londa. O feminismo mudou a ciência?Bauru, Edusc, 2001.

SCOTT, Joan. O enigma da igualdade. Revista Estudos Feministas, 13(1), Florianópolis, jan./abr. 2005, pp.11-30.

SCOTT, Joan. Gênero: Uma categoria útil de análise histórica. Educação \& Realidade, v. 20, n. 2, Porto Alegre, jul./dez., 1995, pp.71-99.

SEDEÑO, Eulalia Pérez. A modo de introducción: lãs mujeres em el sistema de ciencia y tecnología. In: PÉREZ SEDEÑO, Eulalia (ed.). Las mujeres em el sistema de ciencia y tecnología - estudios de casos. Madri, OEI, 2001. 
SILVA, Iraci Pereira da. Escola e relação de gênero: visões de mundo de jovem do ensino médio em Taguatinga. Dissertação (Mestrado em Educação) - Universidade de Brasília, Brasília, 2010 [http://repositorio.unb.br/handle/10482/9070 - acesso em20 nov. 2015].

TELES, Maria Amélia de Almeida. O que são os direitos humanos das mulheres? Brasília, Editora Brasiliense, 2006.

YANNOULAS, Silvia Cristina. Feminização ou feminilização: Apontamentos em torno de uma categoria. Temporalis, ano 11, n. 22, Brasília, jul./dez. 2011, pp.271-292. 